\title{
The long-term role of organic amendments in addressing soil constraints to production
}

\author{
Lukas van Zwieten (iD
}

Received: 19 June 2018/Accepted: 26 June 2018/Published online: 9 July 2018

(C) Springer Nature B.V. 2018

\section{Introduction}

The use of organic amendments such as composts and manures in agricultural production can be traced back to at least the 3rd millennium BC (Wilkinson 1982), where evidence of urban refuse being used in intensive cultivation was found in Iran, Oman and Syria. Foxhall (1998) also reports on historical scrolls that describe the use of cereal byproducts such as straw and chaff in composts and soil amendments for crop production in ancient Greece and Rome. The role of composts and other organic amendments in modern agriculture has perhaps taken a backseat to practices such as the application of synthetic fertilisers, herbicides and mechanical tillage. Arguably, the development of the Haber-Bosch process and synthetic nitrogen $(\mathrm{N})$ fertilisers is the key driver for improved agricultural productivity worldwide. But numerous reports describe a decline in soil quality from intensive tillage practices and a focus on inorganic fertilizer amendments. These include soil acidification, loss of soil organic carbon (SOC), soil structural decline, heavy metal contamination and off-site nutrient

L. van Zwieten ( $\square)$

NSW Department of Primary Industries, Wollongbar,

NSW 2477, Australia

e-mail: lukas.van.zwieten@dpi.nsw.gov.au

L. van Zwieten

Southern Cross Plant Science, Southern Cross University,

Lismore, NSW 2480, Australia effects including emissions of greenhouse gases from soil. There is no question that recycled organic residues are currently underutilised in modern farming systems. This could be due to any number of factors such as uncertainty around benefits and consequences, economic considerations, and lack of supply or supply chains outside of urban areas or regions with intensive animal production facilities. This special issue focuses on identifying and explaining the long-term mechanisms by which composts, manures and other organic amendments can influence crop productivity, profitability and soil fertility.

\section{Addressing nutrient constraints with organic amendments}

Organic amendments can directly supply both macro and micro-nutrients, with the long-term supply of $\mathrm{N}$, in particular, being regulated by the rate of mineralisation of the added organics. Nutrient content is highly dependent upon the source and quality of the organics (Quilty and Cattle 2011). Even within similar products (e.g., Mukai 2018), a high variability in nutrient supply was shown. Manures applied by farmers in subSaharan Africa had a phosphorus (P) content ranging from 0.1 to $0.6 \%$ and a total $\mathrm{N}$ content ranging from 0.6 to $1.7 \%$, suggesting that if these products are used to offset or replace fertilisers, an analysis to determine the quantity of nutrients delivered is required. This 
could be particularly important in sub-Saharan Africa where "the cupboard is still quite bare" in terms of nutrient availability and nutrient application (Bationo et al. 2015). More often than not, the organic amendments are applied in conjunction with mineral fertilisers which may interact depending upon the characteristics of both the organic amendment and the soil. The interactions in soil between organic amendments and chemical fertilisers are complex. Organic amendments including charcoal (Steiner et al. 2008), biochar (Slavich et al. 2013), pig manure or rice straw (Pan et al. 2009) and compost (Vanlauwe et al. 2011) have been shown to beneficially interact with applied nutrients, lowering losses of nutrient from soil and increasing fertiliser use efficiency. This could be through a wide range of mechanisms including improving charge characteristics of the soil, through ameliorating other soil constraints such as low $\mathrm{pH}$ or poor structural properties, through improved microbial processing of nutrients, or through short-term microbial immobilisation of nutrients which lowers their loss due to leaching, nitrification and denitrification.

Meta-analyses have shown that increases in yield from the use of organic amendments can be $60 \%$ greater than in the non-amended control, while combined use of organic amendments and $\mathrm{N}$ fertilisers can result in a yield increase of $114 \%$ (Chivenge et al. 2011). The authors also suggested that long-term residual effects were more pronounced with higher quality organic amendments (here defined as those containing greater than $2.5 \%$ of total N). Similarly, in a study spanning 28 years, Liu et al. (2018) have shown that the annual co-application of horse manure with chemical fertilisers (resulting in an additive nutrient content) can significantly increase the mean yield of corn compared to N, P and potassium (K) fertiliser alone. A study comparing a large oneoff initial application of compost $\left(125 \mathrm{t} \mathrm{Ha}^{-1}\right)$, a lower dose of compost $\left(62.5 \mathrm{t} \mathrm{Ha}^{-1}\right)$ at two occasions but with annual NPK additions and farmer practice consisting of a lower dose of poultry manure with NPK addition (Eldridge et al. 2018) has shown a positive interaction between the compost amendment and the supplied fertilisers. This resulted in greater yield of the vegetable crops in some seasons with the co-application of fertiliser and compost. Importantly, a comprehensive meta-analysis of studies with a duration exceeding 10 years (Chen et al. 2018) has shown that while organic amendments on average will improve crop productivity compared to a nonamended and non-fertilised control, when compared to matched chemical nutrient inputs, few examples of long-term positive benefits to yield were recorded. Exceptions to this were found in soils with a low inherent fertility (total $\mathrm{N}$ and Olsen $\mathrm{P}$ ) and low organic $\mathrm{C}$ content with neutral soil $\mathrm{pH}$, where benefits of the organic amendments were shown to be largely driven by the supply of nutrients. Interestingly, Chen et al. (2018) observed that the dose of organic amendments had no effect on yield, further implying that the principal benefits resulted from nutrient addition, and these were generally met with the lower doses $(<5 \mathrm{t}$ $\mathrm{Ha}^{-1}$ in the current meta-analysis). The authors highlight the need to carefully match the dose of organic amendment with the crop and soil requirement, showing some cases where soil P contents could exceed ideal concentrations, leading to potential negative environmental impacts. Manure amendments significantly increased plant-available $\mathrm{P}$ levels in soil compared to green manures or straw. The slower release of nutrients, particularly $\mathrm{N}$ from manures was highlighted by Mukai (2018), showing that chemical fertilisers have a more important influence on maize yield in the first few years of implementation, while the annual application of manures builds stocks of mineralisable $\mathrm{N}$, which then influence maize yield over the long term. Farmers applied annually between 7 and $209 \mathrm{~kg} \mathrm{~N} \mathrm{Ha}^{-1}$ from manure in this study. Even at the highest dose (209 $\left.\mathrm{kg} \mathrm{N} \mathrm{Ha}^{-1}\right)$, with an assumed $40 \%$ mineralisation during the maize cropping season, around $84 \mathrm{~kg} \mathrm{~N} \mathrm{Ha}^{-1}$ were supplied which was inadequate for maximum maize production. Thus, the co-application of chemical $\mathrm{N}$ to meet crop demand (30 $\mathrm{kg}$ urea $\mathrm{Ha}^{-1}$ ) was recommended.

\section{Other soil constraints addressed by organic amendments}

The importance of SOC in regulating crop yields has been well established (Lal 2004). The accumulation of SOC can benefit crop productivity by increasing the size of the mineralisable $\mathrm{N}$ and $\mathrm{P}$ pool, by improving soil structural properties including lower soil bulk density, improved aggregate stability, improved aeration and pore connectivity, and through ameliorating constraints including inappropriate soil $\mathrm{pH}$ and low 
cation exchange capacity. Strong evidence through meta-analysis was also provided by Chen et al. (2018) for an increase in the soil microbial biomass pool following organic amendments. No differences were detected between application of straw, biosolids or manure suggesting that the quality of organic amendments is less important in regulating microbial biomass.

The long-term changes in SOC following addition of organic amendments showed that on average, the amendments increased SOC by $49 \%$ compared to an unfertilised control or $29 \%$ compared to a fertilised control (Chen et al. 2018). The greatest benefit to SOC and the soil microbial biomass was observed when the starting SOC and N levels were low and when the soils were either neutral or slightly alkaline. Similarly, Eldridge et al. (2018) demonstrated large and significant gains in SOC following compost additions. In an 18 -year study in paddy rice production, Pan et al. (2009) showed a 72 and $103 \%$ increase in SOC following annual manure and straw application, respectively.

\section{Considerations}

This special edition has explored the long-term role of organic amendments on crop yield and soil fertility. Strong evidence was presented on the yield benefits from organic amendments when compared to unfertilised controls. However, no benefits to yield were reported when compared to matched inorganic nutrient controls. Organic amendments can, however, increase the use efficiency of co-applied fertiliser, therefore providing a strategy to maintain and increase yields in the long term. This may be a particularly important strategy where the procurement of chemical fertilisers is limited by their availability or their cost. This aspect was highlighted by Eldridge et al. (2018) where cost-benefit ratios of 2.6-3.3 were achieved for the use of compost in vegetable production compared to existing farmer practice in a 10-crop cycle.

Organic amendments may not provide either an adequate, or a balanced nutrient dose, requiring consideration for both the application of the organic amendment and additional fertilizer. To achieve this, a basic understanding of the characteristics of the amendment is needed, especially the total $\mathrm{N}$ and $\mathrm{P}$ applied via the organic amendment, a good understanding of the crop nutrient demand and existing soil stocks. Cost effective and rapid testing technologies, especially for on-farm decisions, would be an important development to maximise crop benefits and minimise off-site impacts of nutrients.

While organic amendments were shown to build SOC and soil microbial biomass, especially over the long term, there is still a paucity of information on the role of organic amendments in modifying microbial functionality, and how this in turn influences crop productivity. For example, does the increased microbial biomass result in improved nutrient cycling and storage, or development of soil resilience to environmental stressors?

Meta-analysis has shown that responses to organic amendments were generally the greatest in soils with a low initial OC content, and those with neutral or slightly alkaline $\mathrm{pH}$ (Chen et al. 2018). While this should not limit the utilisation of organic amendments in fertile or acidic soils, practitioners working with low organic $\mathrm{C}$ soils may expect greatest benefits from their application. Further investigations are warranted to determine whether liming acidic soils prior to the application of organic amendments would provide additional benefits to yield and soil C storage, compared to the addition of organic matter alone. Alternatively, some organic amendments such alkaline biochars may provide this acid neutralising benefit, therefore blending of organic amendments and fertilisers to better address the soil constraints should be considered.

\section{References}

Bationo A, Lamers J, Lehmann J (2015) Recent achievement of sustainable soil management in sub-Saharan Africa. Nutr Cycl Agroecosyst 102:1-3

Chen Y, Camps-Arbestain M, Shen Q, Singh B, Luz Cayuela M (2018) The long-term role of organic amendments in building soil nutrient fertility: a meta-analysis and review. Nutr Cycl Agroecosyst 111:103-125

Chivenge P, Vanlauwe B, Six J (2011) Does the combined application of organic and mineral nutrient sources influence maize productivity? A meta-analysis. Plant Soil 342:1-30

Eldridge SM, Chan KY, Donovan NJ, Saleh F, Orr L, Barchia I (2018) Agronomic and economic benefits of green-waste compost for peri-urban vegetable production-implications for food security. Nutr Cycl Agroecosyst 111:155-173 
Foxhall L (1998) Snapping up the unconsidered trifles: the use of agricultural residues in ancient Greek and Roman farming. Environ Archaeol 1:35-40

Lal R (2004) Soil carbon sequestration impacts on global climate change and food security. Science 304:1623-1627

Liu P, Zhao H, Li Y, Liu Z, Gao X, Zhang Y, Sun M, Zhong Z, Luo J (2018) Corn yields with organic and inorganic amendments under changing climate. Nutr $\mathrm{Cycl}$ Agroecosyst 111:141-153

Mukai S (2018) Historical role of manure application and its influence on soil nutrients and maize productivity in the semi-arid Ethiopian Rift Valley. Nutr Cycl Agroecosyst 111:127-139

Pan G, Zhou P, Li Z, Smith P, Li L, Qiu D, Zhang X, Xu X, Shen $S$, Chen X (2009) Combined inorganic/organic fertilization enhances $\mathrm{N}$ efficiency and increases rice productivity through organic carbon accumulation in a rice paddy from the Tai Lake region, China. Agric Ecosyst Environ 131:274-280

Quilty JR, Cattle SR (2011) Use and understanding of organic amendments in Australian agriculture: a review. Soil Res 49:1-26
Slavich PG, Sinclair K, Morris SH, Kimber SWL, Downie A, Van Zwieten L (2013) Contrasting effects of manure and green waste biochars on the properties of an acidic ferralsol and productivity of a subtropical pasture. Plant Soil 366:213-227

Steiner C, Glaser B, Teixeira WG, Lehmann J, Blum WEH, Zech W (2008) Nitrogen retention and plant uptake on a highly weathered central Amazonian Ferralsol amended with compost and charcoal. J Plant Nutr Soil Sci 171:893-899

Vanlauwe B, Kihara J, Chivenge P, Pypers P, Coe R, Six J (2011) Agronomic use efficiency of $\mathrm{N}$ fertilizer in maizebased systems in sub-Saharan Africa within the context of integrated soil fertility management. Plant Soil 339:35-50

Wilkinson TJ (1982) The definition of ancient manured zones by means of extensive sherd-sampling techniques. J Field Archaeol 9:323-333 